\section{黑ettsominar ifectures}

\author{
os
}

\section{MIDWIFERY AND DISEASES OF WOMEN.}

Delivered before the Medical Society of London.

BY

C. H. F. ROUTH, M.D.,

PHYSICIAN TO THE SAMARITAN HOSPITAI, FOR WOMEN AND CHILDREN.

LECTURE I.

Ox Some Points connected with the Pathology and Etrology of Fibrous Tumours OF THE UTERUS.

Mr. President and Gentlemen, - I am well aware of the honour of addressing an assembly like the present, including as it does some of the most eminent members of our profession. But if it be an honour, as it undoubtedly is, to have been selected to deliver the Lettsomian Lectures, it involves also a heavy responsibility. Not only have I to emulate the distinguished men who have lectured here before, and deserved well at your hands, but I also feel that I address a body of experienced practitioners-men of knowledge, whose judgment must necessarily be severe. All I can hope is, therefore, that, as I have worked much at the subject, and striven hard to merit your good opinion, I may be leniently listened to, and in offering you something worthy of your attention, not disappoint your expectations altogether.

The subject which I have selected for discussion is "Fibrous Tumours of the Uterus." It is one which has for many years attracted the attention of the profession in every country. Its literature is therefore very extensive; but it is also very widely scattered. I have thought, therefore, as not only do ancient and modern writers hold contradictory views, but as even in the present day authors are not agreed as to the pathology, means of diagnosis, and treatment of these growths, that a general resume might prove interesting and not unprofitable. I propose, therefore, to consider the subject under these three heads, devoting one lecture to each part of the subject; and I trust finally, from this analysis, to deduce certain practical conclusions, which I shall bring prominently before you. Your own future experience will enable you either to confirm my views, if they are founded on fact, or your better judgment to correct them if I have erred, to the adrantage of those whom you treat, and who suffer from this disease.

STrucruRe. What is a fibrous tumour? I should define it as a growth in which the fibro-cellular elements of tissue predominate. To the naked eye it appears to be made up of fibres arranged in bundles, sometimes interlacing, with more or less cellular and even adipose tissue between them, of a white yellowish colour, with tints here and there of light blue. This blue is due to veins or radicles of reins which run through the tissue, the tissue itself being non-vascular. In some instances there is less, in others more cellular tissue present; hence a division made by some into fibrous tumours, properly so called, and fibro-cellular tumours. Sometimes they contain a larger excess of uterine tissue in them; and this constitutes what some have appropriately designated the fleshy tubercle, or, later writers, muscular tumours. All this is simple enough; not so, however, when we look at the subject more scientifically. Here I must confess that my reading on the subject of fibrous tumours, in regard to their classification and division by different authors, has not been very satisfactory. No one, I think, could fail to perceive that there is much verbal confusion, the same word being used by various authors to designate very different varieties. I must therefore content myself with a few general remarks on fibrous tumours as a whole, and then proceed to their classification into varieties, following chiefly in this respect the French school.

When we look closely into a fibrous tumour, it appears to consist of a number of fibres, some of which are parallel, others interlace in every direction, the colouring varying from a light yellow to a light blue. These fibres, which are fibrous tissue, are very resistent, elastic, and closely knit together. Sometimes, but more rarely, they appear to assume the circular form, and to be arranged concentrically around the vessels which pass through them, as figured in the diagram.

Every fibrous tumour is generally surrounded by a capsule, which takes its origin from the uterus, and which is sometimes very closely adherent to the tumour, at other times so little so that the tumour may be easily separated from it or enucleated. This enclosing membrane is itself non-vascular, but serves as a medium for the transmission of the vessels upon which its growth doubtless depends. The veins on the attached uterine surface are much enlarged, this enlargement having a distinct relation to the size of the tumour. Arrived near the tumour, they subdivide into a rete vasculosum, which nourishes the growth precisely in the same manner as in the case of cartilages and other non-vascular tissues. This rete does not, so to say, permeate the tumour. The few large vessels which are exclusively venous, and which sometimes pass through it, end in the rete at the opposed side, and do not belong to the substance of the tumour, resembling in this respect the vessels which permeate fat. Arteries, nerves, and lymphatics have never been discovered in fibrous tumours.

When fibrous tumours are cut through, they either exude no juice, or if so, one which floats upon the water and does not mix with it as encephaloid matter does. Dr. A. Clark, in a communication he kindly favoured me with at my request, has examined especially this juice. He writes-"I have on several occasions examined the juice of succulent fibrous tumours. I can say of it chemically no more than that $I$ have found it always albuminous. Nicroscopically it has varied, but common to all are the following elements :-

"1. Coagulated and variously altered blood-discs, isolated and in heaps.

" 2. Corpuscular forms resembling the white cells of the blood.

"3. Moleculo-granular matter and fat.

"The soft, semi-lardaceous, imperfectly defined fibrous and muscular tumours exhibit, in addition, the following structural forms in the juice :-

"4. Oval flattened corpuscles containing a few granules. 
"5. Fusiform nucleated cells.

"6. Nucleated fibres or fibre-cells resembling the elements of organic muscular fibre."

The microscopical characters of the substance of fibrous tumours themselves are as follows:-1. Fibroplastic elements united together by cellular tissue; 2. Nucleated fibres, striated and muscular in character; 3. A vast number of granular bodies.

The fibro-plastic elements are very closely packed, sometimes straight and sometimes waved. The muscular tissue is best seen after boiling or treating with acetic acid, when the characteristic nuclei become evident. These last fibres exist in vast numbers, considerably more abundant than in the ordinary unimpregnated uterus, but less so than in the pregnant organ. Indeed, according to Robin, they constitute at least from one-fourth to one-half the entire morbid mass. This circumstance it was that led Vogel to assert that fibrous tumours were, after all, a mere hypertrophy of the muscular tissue in the uterus.

"The granular bodies consist of an amorphous mass, very tenacious, semi-solid, keeping the fibres firmly adherent one to another, so as in fact to mask them. This element is most important in regard to the part it plays in the harder tumour, and is especially abundant in those examples where the tumours have assumed a somewhat semi-transparent aspect" (Guyon).

Varieties. As to classification, I shall venture to speak of fibrous tumours of the uterus as of three classes: 1. Fibromas, which include hysteromas; 2. Fibroids, including the recurrent; 3. Malignant, as occurring both among fibromas and fibroids.

1. Fibromas are homologous tumours developed in a specitic blastema resembling permanent fibrous tissue; differing, however, from it in this respect, that they have the power of independent growth, and of enlarging and developing indetinitely. Un examination by the naked eye, we can make out two varieties: one, homogeneous-looking when cut through, shining, with no appearance of fibres, which, however, are soon developed by maceration in alcohol; another presenting distinctly the appearance of opaque fibres, sometimes white, grey, or yellow, and crossed in various directions. (Costello.)

As I am speaking, however, of fibrous tumours as they are found in the uterus only, I pass on to speak of the most common variety found in the uterus, namely, hysteromas.

Hysteromas, so called from their resemblance to uterine tissue, and their frequent presence as pathological results in that organ, contain, in addition to the fibrous elements of fibrous tissue, distinct fibrocellules, alias the fibres of Kölliker; in other words, the muscular tissue of organic life. These hysteromas constitute the fibroids of Lebert, and differ from fibromas in their benignity, and in never ulcerating spontaneously.

These muscular organic fibres are distinguished by $M$. Lebert from fibro-plastic bodies (to which I shall presently refer) by a certain number of characters. The nuclei are narrower and more elongated. They have only one nucleolus: some are bent upon themselves. The fusiform bodies themselves are longer and thinner, as if unwoven. These bodies often exist in very large quantities in fibrous tumours, and sometimes it has been clearly made out that these are pediculated, and directly continuous with the uterine tissue. In other cases they are isolated; but M. Lebert is still convinced that they proceed from the muscular fibres of the uterus, and partake of their character. These productions are included by him under the name of homologous growths. Just as an exostosis borrows from the neighbouring bone its general characters, or a cyst contains epithelium like its neighbouring cavity, so these fibrous tumours borrow muscular fibres from the contiguous uterus. The uterus here only follows the general law, that every organ exercises a sort of especial attraction on the nutritive elements which maintain it. Any deviation from health may determine an analogous production in its neighbourhood (Bullet. de la Soc. Anat., p. 324, vol. ii).

It was the frequent presence of these bodies that led Vogel to assert that a fibrous tumour was always a hypertrophy of the uterine organ, a fact referred to long since by Dr. Oldham. The later inquiries of Dr. Bristowe, well known to most of you as an accurate observer, have fully confirmed this view, more especially in relation to the pregnant state. That gentleman examined two specimens of fibrous tumour in pregnant uteri. The first had during life been supposed to be an exostosis, which led to the performance of the Crsarean section and the death of the patient. The fibrous tumours after death were here found to be solely connected with the upper two-thirds of the posterior wall of the uterus, and formed an irregular lobulated pedunculated mass of about the size of an orange. On section, it was found that the muscular tissue of the uterus enveloped some of the tumours, but in others extended merely for a short distance at their base. The tumours presented the ordinary characters of fibrous tumours, only they were denser, somewhat fleshy in appearance, and constituted of fibres, curving and twisting in all directions with the utmost complexity.

The microscopic examination of the tumours was conducted with great care.

"Portions of different tumours (taking care not to mistake any of the muscular tissue enveloping the tumours themselves) were submitted to examination, and, contrary to anticipation, in all instances, without exception, were found to present precisely the same characters as the muscular tissue of the uterus itself. They were so similar, indeed, that it was quite impossible to say of any specimen observed under the microscope whether it was taken from the normal or abnormal structure. The tumours consisted of fusiform pellucid fasciculated muscular fibres, identical in size, shape, general appearance, and arrangement with those of the uterine parietes. There did not appear to be more fibrous tissue in these than in the uterus, although the fibrous tumours felt more dense."

Dr. Bristowe also examined another specimen of a fibrous tumour. This patient died four days after delivery, and the tumour was found, as in the latter case, to be made of muscular tissue. The fibres only were a little corrugated, as the tumour had for several years been kept in Goadby's solution (Path. Trans., vol. iv). And this appears to be now the opinion generally held by French and German pathologists, even by Lebert. That learned pathologist has now confessed openly that, although at the first he hesitated to admit the identity of fibrous tumours of the uterus with the uterus itself, believing that the fusiform bodies met in them were of a fibro- 
plastic nature, a more attentive examination has not allowed him to remain any longer in ignorance of their muscular structure and general resemblance to the uterine organ.

[To be continued.]

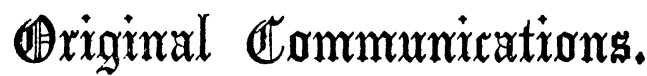

\section{ILLUSTRATIONS OF THE DIFFERENT} FORMS OF INSANITY.

By W. H. O. SANKey, M.D.Lond., Medical Superintendent of the Female Department of the

Hanwell Asylum.

[Continued from page 35.7

There remains to be described the form of melancholy called hypochondriasis. Two types or two stages of this form have been described by authors; but, though most writers agree in making these two types, the line of division between them does not appear to be the same with all. The definition of hypochondriasis being a malady in which the patient has false conceptions on the subject of his bodily health, some writers would appear to make their division rest between a hypochondriasis without mental aberration, and one with it. They seem to say, also, that one form merges into the other. When diseases do this, they cannot be said to be distinct. As these papers are professedly from clinical observation, I shall here describe only what I have met with in my own practice. There appear to me to be two types, the line of demarcation being sufficiently distinct in typical cases.

The first form or type, or hypochondriasis proper, is met with but seldom in asylums for the insane. Dr. Watson designates the patient with this malady " a plague to his physician, as well as to himself." It is a disease less frequent among females.

This disease has been called also nosomania. Cases are known to terminate in well-marked insanity and in suicide; and yet, in the early stage, patients suffering from it are seldom "found insane"; but, in a purely pathological sense, unsoundness of mind must exist in all its progress. It has already been shown that in other forms of melancholy, or melancholic insanity, the moral affections are the first involved. In the early stages of all hypochondriacal cases, it is the moral affections, the instincts, which are chiefly implicated. The intellect, in many of the cases narrated, remained comparatively clear for some period after the setting in of the other symptoms. In a typical case of true hypochondriasis, the intellect usually remains for a still longer time clear. The patient may so far retain his intellectual faculties as to be able to converse, argue, reason, remember, etc., correctly; yet on some subjects, especially such as relate to his bodily condition and health, he entertains an erroneous notion. It will be conceded that we possess naturally an instinctive consciousness of health, and of absence of health-disease; and it is obviously a false notion or belief to consider ourselves ill when we are well, or to believe ourselves diseased when we are whole.

This error is not one of reasoning, nor a judgment resulting from a complex mental operation, which might be liable to fail in any of its stages. It is a simple instinctive feeling that is altered. The perverted instinct which leads to the belief, or the in- tellect which yields to the false impression, are cerebral acts; and, these being perverted obviously by bodily disease, the nature of the malady must be considered a form of mental disease.

The second type of hypochondriasis is very obscurely described by writers. I have been in the habit of including under this name certain cases not at all uncommon in asylums, in which the mind of the patient is more or less completely occupied with the state of the bodily health or condition. These patients do not display the same anxiety to apply remedies as the other or true hypochondriacs. The false perception is a part of their mental disease; they appear to accept their lot as one not amenable to medical treatment. These patients are mostly melancholy or depressed. It will be sufficient, perhaps, to enumerate some of the delusions that I have observed in my own practice as illustrating this description of disease ; and it will be observed that these cases approach the true form of hypochondriasis only in the accidental circumstance, that their illusions or delusions have more or less direct reference to their bodily health or condition. Early writers included all those cases under hypochondriasis in which the sufferer imagined he was made of glass, and was in constant fear of breaking; or was made of butter, and was afraid of melting.

I have known a great variety of instances in which extraordinary delusions haunted the patients continually, which would belong to the same category as the above; but the cases would fall under different divisions in the classification of insanity, as under monomania, chronic mania, etc. It may be convenient to enumerate some of the chief in this place, remarking that these strange vagaries of the mind occur chiefly in confirmed cases, especially when the false ideas involve an operation of the intellect proper; but when they are confined to anomalies of the instincts, they may occur at an earlier stage of the disease. These cases form, in fact, no exception to the law that the moral faculties are the first involved; that the anomalies of the intellectual faculties, as illusion and delusion, occur subsequently, generally at a much later period of the case.

It is not uncommon to meet with melancholic patients who assert that they have no gullet; that they have no passage from the bowels, or from the womb; that they have no inside; that they are hollow, etc. In cases already related, several of the patients entertained the belief that they did not require food. A patient at present under treatment believes that she has an internal cancer, and she has been an in-patient at nearly all the London hospitals. Another, who died of exhaustion during the present year, believed she was putrefying; that it was unfit for her to be with others; that her womb was diseased; and this delusion was stated to have been aggravated after an examination by the speculum prior to admission.

I had a patient who was many years under the delusion that she gave birth to hundreds of children daily. I have a second, admitted pregnant, whose infant is now about six months old; on admission, she had the delusion that she gave birth to one hundred children every day, but, since her confinement, has reduced the daily number to eight or ten.

A young melancholic female, formerly epileptic, and of very slender proportions, believed that she was of such enormous bulk and height, that she was much ashamed to be seen. Another woman, enormously stout, believes herself to be a sylph, and is afraid of being blown away.

An old lady believes she is a bird, and calls her grey locks feathers. She is a buxom body of fifteen or sixteen stone, and above sixty years of age; and 